\title{
Extraction of Trace Amounts of Copper(II) on a Membrane Filter Using 5,10,15,20-Tetraphenyl-21H,23H-porphinetetrasulfonic Acid for the Determination by Solid-Phase Spectrophotometry
}

\author{
Toshio ShIMIzU, Isoshi NuKatsuka and Kunio OHzeKi ${ }^{\dagger}$ \\ Department of Materials Science and Technology, Faculty of Science and Technology, Hirosaki University, \\ Hirosaki 036-8561, Japan
}

\begin{abstract}
A highly sensitive solid-phase spectrophotometric method for the determination of trace amounts of copper(II) using 5,10,15,20-tetraphenyl-21H,23H-porphinetetrasulfonic acid (TPPS) is described. The copper(II)-TPPS complex was extracted on a membrane filter from an acidic solution containing Zephiramine (benzyldimethyltetradecylammonium chloride) and a large excess of perchlorate ion, leaving excess TPPS in the solution. The solid-phase absorbance of the copper(II)-TPPS complex on the membrane filter was measured at $417 \mathrm{~nm}$. A linear calibration graph was obtained for up to $20 \mathrm{ng}$ of copper(II) in a $20 \mathrm{ml}$ sample volume; the limit of detection was $0.15 \mathrm{ng}$, based on three-times the standard deviation of the blank value. The proposed method was applied to the determination of copper in tap, river and sea water samples. The results are in fair agreement with those obtained by suspension-introduction graphite-furnace atomic absorption spectrometry using ammonium pyrrolidinedithiocarbamate and finely divided anion-exchange resin.
\end{abstract}

Keywords Copper, membrane extraction, tetraphenylporphinetetrasulfonic acid, solid-phase spectrophotometry, resin suspension-introduction GFAAS

Solid-phase spectrophotometry using a membrane filter is based on the extraction of a desired trace element as a colored species on the filter, and a direct absorbance measurement of the resulting colored thin layer by spectrophotometry. ${ }^{1-4}$ The formation of a hydrophobic species is required for a quantitative extraction of the desired trace element on the filter. ${ }^{5} \mathrm{~A}$ combination of Zephiramine (benzyldimethyltetradecylammonium chloride) and a large excess of perchlorate ion is useful for the extraction of water-soluble anionic species ${ }^{3}$, in which an ion-association complex formed between Zephiramine and the anionic species is extracted together with the ion-pair precipitate formed between Zephiramine and perchlorate ions.

Porphyrins are highly sensitive reagents for the determination of trace metals ${ }^{6}$, and copper at ppb levels was determined without preconcentration. ${ }^{7-10}$ The sensitivity of the determination of copper with porphyrins was further improved by solvent extraction ${ }^{11}$ and solidphase extraction using ion-exchange resin ${ }^{12,13}$ and membrane filter; ${ }^{14}$ however, a method of higher sensitivity is still required for the determination of copper in smaller sample volumes.

The aim of this study was to develop a method of solid-phase spectrophotometry for the determination of trace amounts of copper at sub-ppb levels. 5,10,15,20Tetraphenyl-21H,23H-porphinetetrasulfonic acid (TPPS) was selected for this purpose, and the condi-

$\doteqdot$ To whom correspondence should be addressed. tions to extract the copper(II)-TPPS complex without extraction of the excess TPPS were investigated. Suspension-introduction graphite-furnace atomic absorption spectrometry ${ }^{15}$ was also examined and the results of the determination of copper were compared with each other.

\section{Experimental}

\section{Apparatus}

A Shimadzu UV-Visible recording spectrophotometer (Model UV-160A) was used for measuring the absorbance of a copper(II)-TPPS complex on a membrane filter. A Hitachi Zeeman effect GFAAS (Model Z-8270) with an auto-sampler (Model SSC-300) was used for measuring the atomic absorption of copper in a resin suspension. A Toyo KG-25 filter holder was used with a membrane filter of cellulose nitrate $(0.45$ or 0.65 $\mu \mathrm{m}$ pore size, Toyo Advantic). A Branson Ultrasonic Cleaner B-42 was used for preparing the resin suspension.

\section{Reagents}

All reagents used were of analytical grade. Doubly distilled water was used. ${ }^{15}$ A stock copper(II) solution (100 $\mathrm{mg}^{-1}$ ) was prepared by dissolving copper sulfate pentahydrate (Wako Pure Chemical) in $0.1 \mathrm{M}$ hydrochloric acid. A working solution $\left(100 \mu \mathrm{g} \mathrm{l}^{-1}\right)$ was prepared from the stock solution by dilution with 0.1 
mol $\mathrm{l}^{-1}$ hydrochloric acid. A $0.10 \mathrm{mmol} \mathrm{l}^{-1}$ TPPS solution was prepared by dissolving the Dotite reagent (Dojindo Lab.), 5,10,15,20-tetraphenyl-21 H,23H-porphinetetrasulfonic acid, disulfuric acid, tetrahydrate in water. A $10 \%(\mathrm{w} / \mathrm{v})$ ascorbic acid solution was prepared fresh daily. A $10 \mathrm{mmol} \mathrm{l}^{-1}$ Zephiramine (Zeph) solution was prepared by dissolving the Dotite reagent, benzyldimethyltetradecylammonium chloride dihydrate in water. A $2 \mathrm{~mol} \mathrm{l}^{-1}$ sodium acetate solution and a 3 mol $1^{-1}$ sodium perchlorate solution were prepared by dissolving the respective salts in water. A $10 \mathrm{mmol} \mathrm{l}^{-1}$ ammonium pyrrolidinedithiocarbamate (APDC) solution was prepared by dissolving a reagent of special grade for AAS (Wako Pure Chemical) in water. An anion-exchange resin suspension (ARS) prepared from a macroreticular-type Diaion PA 318 (Mitsubishi Kagaku) was used. ${ }^{15}$ The ion-exchange capacity was $14.6 \mu$ equiv $\mathrm{cm}^{-3}$.

\section{Extraction of TPPS on a membrane filter}

A sample aliquot of less than $30 \mathrm{ml}$ containing 20 nmol of TPPS, $10 \mu \mathrm{mol}$ of EDTA, $3 \mathrm{mmol}$ of sodium chloride or sodium perchlorate was taken in a $150 \mathrm{ml}$ polypropylene beaker. After the $\mathrm{pH}$ was adjusted to 6 or 1 , the mixture was kept at $20^{\circ} \mathrm{C}$ for $10 \mathrm{~min}$; also, varying amounts of Zeph were added, while keeping the final sample volume at $30 \mathrm{ml}$. The whole was mixed well by swirling; it was then filtered through a $0.65 \mu \mathrm{m}$ membrane filter. The filtrate was collected in a $50 \mathrm{ml}$ volumetric flask. The filter was removed and the filter support was washed with $5 \mathrm{ml}$ of $3 \mathrm{~mol} \mathrm{l}^{-1}$ perchloric acid and the washings were combined with the filtrate. The whole was diluted to $50 \mathrm{ml}$ with water and the absorbance of the resulting solution was measured at $434 \mathrm{~nm}$. The percent extraction was calculated from the resulting absorbance-pH curve.

General procedure for the solid phase spectrophotometric determination of copper(II)

A $20 \mathrm{ml}$ aliquot of the solution ( $\mathrm{pH}$ 2) containing less than $20.0 \mathrm{ng}$ of copper(II) was placed in a $150 \mathrm{ml}$ polypropylene beaker. A $0.1 \mathrm{ml}$ portion of $0.1 \mathrm{mmol} \mathrm{l}^{-1}$ TPPS, $0.45 \mathrm{ml}$ of $10 \%\left(0.57 \mathrm{~mol} \mathrm{l}^{-1}\right)$ ascorbic acid and $5 \mathrm{ml}$ of $2 \mathrm{~mol} \mathrm{l}^{-1}$ sodium acetate solutions were added successively, the $\mathrm{pH}$ of the resulting solution being about 6. After standing the mixture at $20^{\circ} \mathrm{C}$ for $10 \mathrm{~min}$, $2.5 \mathrm{ml}$ of $20 \%\left(6 \mathrm{~mol} \mathrm{l}^{-1}\right)$ hydrochloric acid was added to adjust the solution $\mathrm{pH}$ to 1 . A $1 \mathrm{ml}$ portion of $3 \mathrm{~mol}$ $\mathrm{l}^{-1}$ sodium perchlorate and $2 \mathrm{ml}$ of $10 \mathrm{mmol} \mathrm{l}^{-1}$ Zeph solutions were added successively, and the whole was mixed well by swirling; it was then filtered through a $0.65 \mu \mathrm{m}$ membrane filter. The copper(II)-TPPS-Zeph complex was thus collected on the filter, together with Zeph-perchlorate ion-pair precipitate, as a circular thin layer $c a .17 \mathrm{~mm}$ in diameter. The filter was kept wet with $0.1 \mathrm{~mol} \mathrm{l}^{-1}$ perchloric acid and placed on a quartz plate attached to the sample-side window of the detector of the spectrophotometer. A wet fresh membrane filter was placed on a quartz plate attached to the refer- ence-side window, and the absorbance was measured at $417 \mathrm{~nm}$. A blank thin layer was prepared using the same procedure, except that no copper(II) was added, and the absorbance was also determined.

\section{General procedure for the resin-suspension introduction GFAAS}

A $50 \mathrm{ml}$ aliquot of the solution ( $\mathrm{pH}$ 2) containing less than $30.0 \mathrm{ng}$ of copper(II) was placed in a $150 \mathrm{ml}$ polypropylene beaker; then, $1 \mathrm{ml}$ of $0.2 \mathrm{~mol} \mathrm{l}^{-1}$ EDTA, $1 \mathrm{ml}$ of $3 \mathrm{~mol} \mathrm{l}^{-1}$ sodium perchlorate, $2 \mathrm{ml}$ of $10 \mathrm{mmol}$ $\mathrm{1}^{-1}$ APDC, and $0.5 \mathrm{ml}$ ARS were added successively. After stirring for $5 \mathrm{~min}$, the resin particles were collected on a $0.45 \mu \mathrm{m}$ membrane filter. The membrane filter holding the resin thin layer was placed in a $10 \mathrm{ml}$ beaker and a $1.0 \mathrm{ml}$ portion of $0.1 \mathrm{~mol} \mathrm{l}^{-1}$ hydrochloric acid was added. The beaker was covered with a piece of Selon film (Fuji Photo Film) and subjected to ultrasonic irradiation for $90 \mathrm{~s}$. The resulting resin suspension was then placed in a cup for the automatic sampler. The cup was shaken by hand just before automatic sampling; then, a $20 \mu \mathrm{l}$ portion of the suspension was injected to the graphite cuvette. After the sample was dried at $80-140^{\circ} \mathrm{C}$ for $40 \mathrm{~s}$, ashed at $600^{\circ} \mathrm{C}$ for $30 \mathrm{~s}$ and atomized at $2700^{\circ} \mathrm{C}$ for $5 \mathrm{~s}$, the absorbance at 324.8 $\mathrm{nm}$ was measured.

\section{Results and Discussion}

Effects of the $\mathrm{pH}$, Zephiramine ion and perchlorate ion on the extraction of TPPS

The effect of Zeph on the extraction of TPPS was examined at $\mathrm{pH} 6$ and 1 in the presence of sodium chloride or sodium perchlorate, according to a general procedure, in which EDTA was added to mask the impurity copper in the solution. Since the $\mathrm{p} K_{\mathrm{a}}$ values for the diacidic form of TPPS-trisulfonate, $\left(\mathrm{H}^{+}\right)_{2} \mathrm{H}_{2} \mathrm{tpps}^{3-}$, were reported as $\mathrm{p} K_{\mathrm{a} 1}=4.86$ and $\mathrm{p} K_{\mathrm{a} 2}=4.95^{7}$, and almost the same values were expected for $\left(\mathrm{H}^{+}\right)_{2} \mathrm{H}_{2}$ tpps ${ }^{4-}$, the predominant species of TPPS were estimated to be $\mathrm{H}_{2}$ tpps ${ }^{4-}$ at $\mathrm{pH} 6$ and $\left(\mathrm{H}^{+}\right)_{2} \mathrm{H}_{2}$ tpps $^{4-}$ at $\mathrm{pH} 1$, respectively. At $\mathrm{pH} \mathrm{6}$, the extraction of TPPS was increased with increasing amounts of Zeph added; a constant and maximum absorbance was attained at a molar ratio of Zeph to TPPS ions above 4, as shown by A in Fig.1, which clearly indicated that TPPS is extracted as an ion-association complex with Zeph, $\left[\mathrm{H}_{2} \mathrm{tpps}^{4-}\right]\left[\mathrm{Zeph}^{+}\right]_{4}$, even in the presence of $0.1 \mathrm{~mol} \mathrm{l}^{-1}$ chloride ion. On the other hand, great amounts of Zeph were required to extract TPPS from a solution of $\mathrm{pH}$ 1, as shown by B in Fig. 1, because the formation of the ion-pair between the anionic side-chain of the porphyrin and Zeph cation was disturbed by repulsion from the positively charged porphyrin ring. As shown by $\mathrm{C}$ in Fig. 1, the extraction of TPPS was well suppressed in the presence of a large excess of perchlorate ion over Zeph, because almost all of the Zeph ions were associated with the perchlorate ion to form the ion-pair precipitate. 


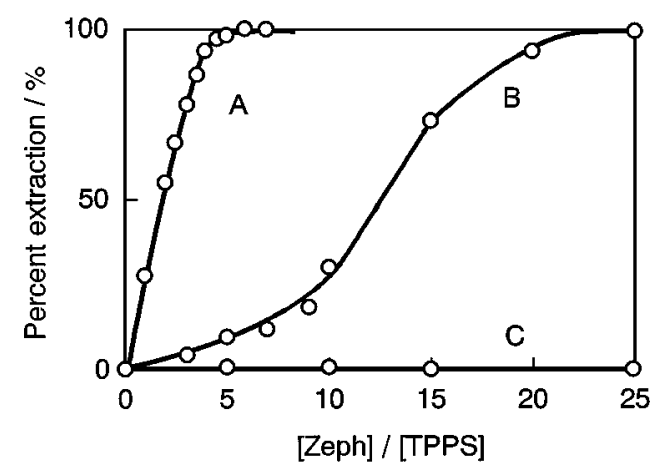

Fig. 1 Effect of the amount of Zeph on the extraction of TPPS. TPPS, $20 \mathrm{nmol}$; sample volume, $30 \mathrm{ml}$; A, pH 6 in the presence of $0.1 \mathrm{~mol} \mathrm{l}^{-1}$ sodium chloride; $\mathrm{B}, \mathrm{pH} 1$ in the presence of $0.1 \mathrm{~mol} \mathrm{l}^{-1}$ sodium chloride; $\mathrm{C}, \mathrm{pH} 1$ in the presence of $0.1 \mathrm{~mol}^{-1}$ sodium perchlorate

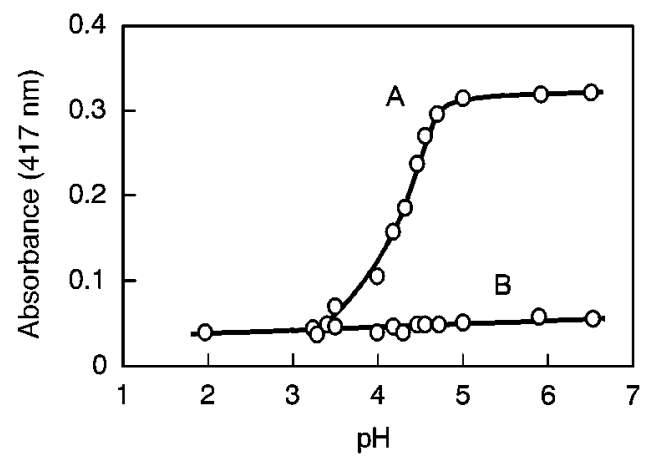

Fig. 2 Effect of the $\mathrm{pH}$ on the formation of the copper(II)TPPS complex. A, sample; B, blank. Reaction conditions: copper, $20.0 \mathrm{ng}$; TPPS, $10 \mathrm{nmol}$, ascorbic acid, $0.26 \mathrm{mmol}$; sample volume, $25 \mathrm{ml} ; 20^{\circ} \mathrm{C}, 10 \mathrm{~min}$. Extraction conditions: pH 1; sodium perchlorate, 3 mmol; Zeph, $20 \mu \mathrm{mol}$; final sample volume, $30 \mathrm{ml}$.

Effects of the $\mathrm{pH}$, Zephiramine ion and perchlorate ion on the extraction of the copper(II)-TPPS complex

The effect of the $\mathrm{pH}$ on the formation of the copper(II)-TPPS complex was examined after extraction of the resulting copper(II)-TPPS complex on a membrane filter according to the general procedure, in which the addition of ascorbic acid was essential for the rapid formation of the copper(II)-TPPS complex. ${ }^{9,16}$ The absorbance due to the formation of the copper(II)TPPS complex increased rapidly above $\mathrm{pH} 3.25$ and a constant and maximum absorbance was observed above $\mathrm{pH} \mathrm{5}$, as shown in Fig. 2, while the blank value increased slightly with increasing $\mathrm{pHs}$ in the range 2 6.5. The copper(II)-TPPS complex once formed was stable and extracted from solutions in the $\mathrm{pH}$ range $0.8-2.0$ studied, while keeping almost all the excess TPPS in the solution.

The absorption spectrum of the copper(II)-TPPS complex on a membrane filter had a maximum at 417 nm, as shown in Fig. 3. The blank absorbance was partly due to impurity copper in the reagent used and

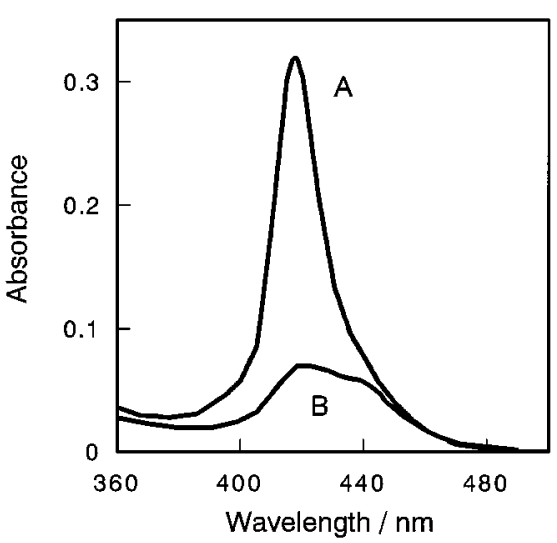

Fig. 3 Absorption spectra of the copper(II)-TPPS complex on a membrane filter. A, sample; $\mathrm{B}$, blank, reaction $\mathrm{pH}, 6$. The other conditions were the same as in Fig. 2.

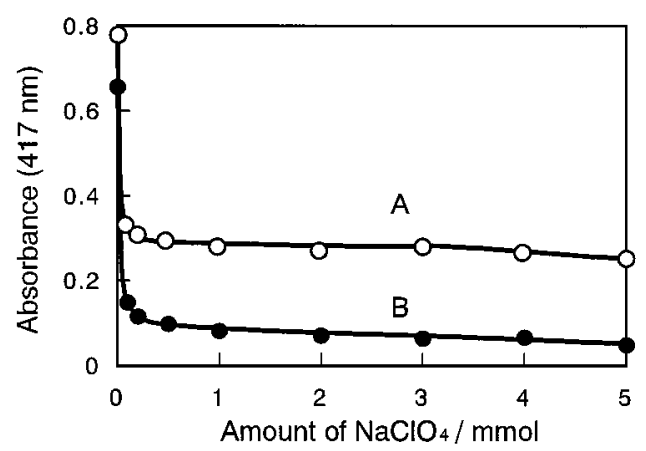

Fig. 4 Effect of the amount of sodium perchlorate on the extraction of the copper(II)-TPPS complex. A, sample; B, blank. The other conditions were the same as in Fig. 3.

partly due to TPPS remaining on the filter. In analogy with the extraction of TPPS with Zeph, the extracted copper species was estimated to be $\left[\mathrm{Cu}(\mathrm{tpps})^{4}\right]\left[\mathrm{Zeph}^{+}\right]_{4}$. The copper(II)-TPPS complex extracted on the membrane filter was stable and a constant absorbance was obtained for at least $60 \mathrm{~min}$ when the filter was kept wet with $0.1 \mathrm{~mol} \mathrm{l}^{-1}$ perchloric acid.

The effect of the amount of sodium perchlorate was examined. Although the copper(II)-TPPS complex was extracted on a membrane filter with Zeph, even in the absence of perchlorate ion, as shown in Fig. 4, the addition of perchlorate ion was essentially necessary to suppress the extraction of TPPS.

The effect of the amount of Zeph was also studied. The absorbance due to the copper(II)-TPPS complex was increased as increasing amounts of Zeph were added, as shown in Fig. 5, in which a sharp increase in the absorbance was mainly due to an increase in the recovery of the copper(II)-TPPS complex; also, a gradual increase in the absorbance was mainly due to an increase in the effective path-length as the thickness of the thin layer of the precipitate increased. 


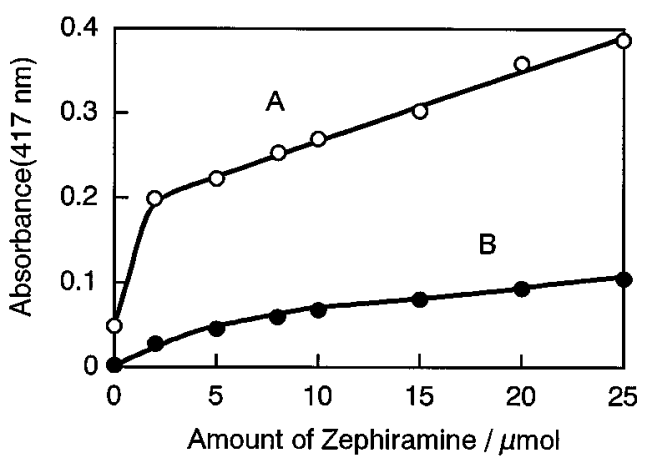

Fig. 5 Effect of the amount of Zeph on the extraction of the copper(II)-TPPS complex. A, sample; B, blank. The other conditions were the same as in Fig. 3.

\section{Calibration graph}

A linear calibration graph was obtained as $y=0.0121 x+0.075$ ( $r=0.9995$ ) for up to $20.0 \mathrm{ng}$ of copper(II) in $20 \mathrm{ml}$ of sample aliquots, where $y$ is the absorbance, including the blank value obtained against a fresh membrane filter and $x$ is the amount of copper(II) in nanograms. As the amount of copper increased beyond $20 \mathrm{ng}$, the slope of the calibration curve decreased slightly. The relative standard deviation $(n=8)$ was $1.8 \%$ for $10.0 \mathrm{ng}$ of copper(II), and the limit of detection was $0.15 \mathrm{ng}$ of copper, based on three-times the standard deviation of the blank value. A calibration graph obtained from $30-\mathrm{ml}$ aliquots, $y=0.0122 x+0.090(r=0.9996)$ for up to $20 \mathrm{ng}$ of copper(II), indicated that although the blank absorbance was increased with increasing sample volume, the net absorbance due to copper was constant.

\section{Effect of foreign ions}

The effects of $10 \mu \mathrm{g}$ of aluminum(III), iron(III), cadmium(II), manganese(II), nickel(II), cobalt(II), zinc(II), and lead(II) were separately examined in the determination of $10 \mathrm{ng}$ of copper(II). The relative errors for the determination of copper(II) were found to be in the range -3.9 to $2.7 \%$; it was thus safely concluded that these cations did not affect the determination of copper(II). Although the copper(II)-TPPS complex was effectively extracted on a membrane filter from a solution containing $0.6 \mathrm{~mol} \mathrm{l}^{-1}$ sodium chloride, a reaction time of more than 14 min was required for full coloration of the copper(II)-TPPS complex. The complexation between $20 \mathrm{ng}$ of copper(II) and $10 \mathrm{nmol}$ of TPPS at pH 6 was completely masked in the presence of $50 \mathrm{nmol}$ of EDTA.

\section{Determination of copper by suspension-introduction GFAAS}

For a comparison of the results obtained by solidphase spectrophotometry with another method, suspension-introduction GF-AAS was selected. A combination of a finely divided anion-exchange resin and APDC was examined, since it had already been suc-
Table 1 Results of the determination of copper

\begin{tabular}{|c|c|c|c|c|}
\hline \multirow{2}{*}{ Sample } & \multirow{2}{*}{$\begin{array}{l}\text { Amount } \\
\text { taken/ml }\end{array}$} & \multicolumn{2}{|c|}{ Copper found, ppb } & \multirow{2}{*}{$\begin{array}{r}\text { No. of } \\
\text { analyses }\end{array}$} \\
\hline & & Mean & SD & \\
\hline \multicolumn{5}{|c|}{ Tap water (Hirosaki city) } \\
\hline TPPS & 10.0 & 1.10 & 0.03 & 6 \\
\hline GFAAS & 20.0 & 1.12 & 0.03 & 3 \\
\hline \multicolumn{5}{|c|}{ River water (Iwaki river) } \\
\hline TPPS & 15.0 & 0.71 & 0.02 & 4 \\
\hline GFAAS & 30.0 & 0.72 & 0.04 & 4 \\
\hline \multicolumn{5}{|c|}{ Seawater (Fukaura coast) } \\
\hline TPPS & 30.0 & 0.37 & 0.01 & 4 \\
\hline GFAAS & 50.0 & 0.37 & 0.02 & 4 \\
\hline
\end{tabular}

cessfully applied for the concentration of trace amounts of lead and cadmium present in tap water. ${ }^{15}$

In the presence of $20 \mu \mathrm{mol}$ EDTA, as described in the general procedure, a constant and maximum absorbance due to copper in the resulting resin suspension was obtained in the $\mathrm{pH}$ range $1-6$. The absorbance was then rapidly decreased above $\mathrm{pH} 6$, because of the formation of the copper(II)-EDTA complex, which could not be fixed on the resin. The selectivity of the extraction of the copper(II)-APDC complex from a solution of $\mathrm{pH} 2$ could be improved in the presence of EDTA, since diverse cations, such as iron(III), were masked with EDTA.

With the use of $0.50 \mathrm{ml}$ of ARS with $14.6 \mu$ equiv $\mathrm{cm}^{-3}$, a constant recovery of $30 \mathrm{ng}$ of copper was attained from different sample volumes in the 30-200 $\mathrm{ml}$ range. The addition of sodium perchlorate was necessary to make the filtration rapid..$^{15}$

The resin particles holding the copper-APDC complex were suspended in $0.1 \mathrm{M}$ hydrochloric acid by ultrasonic irradiation. Irradiation for more than $60 \mathrm{~s}$ was required to obtain a constant and maximum absorbance of copper in the resulting resin suspension.

A typical calibration graph obtained from $50 \mathrm{ml}$ of sample aliquots can be expressed as $y=0.0098 x+0.015$ ( $r=0.9981$ ) for up to $30.0 \mathrm{ng}$ of copper(II), where $y$ is the absorbance due to copper in $1.0 \mathrm{ml}$ of the final suspension, including the blank value, and $x$ is the amount of copper(II) in nanograms. The relative standard deviation $(n=3)$ was $2.0 \%$ for $20.0 \mathrm{ng}$ of copper(II) and the detection limit was $0.56 \mathrm{ng}$ of copper, based on threetimes the standard deviation $(n=3)$ of the blank value.

\section{Determination of copper in water samples}

River water and seawater samples were acidified to $\mathrm{pH} 2$ with the addition of hydrochloric acid and filtered through a $0.45 \mu \mathrm{m}$ membrane filter before they were subjected to the determination by solid-phase spectrophotometry and suspension-introduction GFAAS. A tap-water sample was also acidified and subjected to a determination without filtration. More than 12 min was required for full coloration of the copper(II)-TPPS complex in a seawater sample, while it was completed 
at least within 2 min in tap- and river-water samples. The slow formation of the copper(II)-TPPS complex in the seawater sample was mainly due to the high ionic strength; however, the same tendency can be expected if copper in seawater has been complexed with naturally occurring complexing agents.

The results of the determination of copper are summarized in Table 1. Both results were found to be in fair agreement with each other, and the accuracy of the results have been confirmed.

\section{References}

1. D. E. Ryan and J. Holzbecher, Can. J. Chem., 53, 311 (1975).

2. K. Ohzeki, C. Toki, R. Ishida and T. Saitoh, Analyst [London], 112, 1689 (1987).

3. K. Ohzeki, T. Uno, I. Nukatsuka and R. Ishida, Analyst [London], 113, 1545 (1988).

4. C. Shima, I. Nukatsuka and K. Ohzeki, Anal. Sci., 14, 337 (1998).
5. K. Ohzeki, M. Minorikawa, Y. Yokota, I. Nukatsuka and R. Ishida, Analyst [London], 115, 23 (1990).

6. K. L. Chen, K. Ueno and T. Imamura, "Handbook of Organic Analytical Reagents", p. 355, CRC Press, Boca Raton, 1982.

7. J. Itoh, T. Yotsuyanagi and K. Aomura, Anal. Chim. Acta, 74, 53 (1975).

8. H. Ishii and H. Koh, Talanta, 24, 417 (1977).

9. H. Ishii and H. Koh, Bunseki Kagaku, 28, 473 (1979).

10. H. Ishii, H. Koh and K. Satoh, Bunseki Kagaku, 31, E389 (1979).

11. M. Tabata and K. Kaneko, Analyst [London], 116, 1185 (1991).

12. K. Yoshimura, S. Nigo and T. Tarutani, Talanta, 29, 173 (1982).

13. H. Ishii, Fresenius' Z. Anal. Chem., 319, 23 (1984).

14. J. Itoh and M. Komata, Mikrochim. Acta, 106, 109 (1992).

15. K. Anezaki, X. Chen, T. Ogasawara, I. Nukatsuka and K. Ohzeki, Anal. Sci., 14, 523 (1998).

16. M. Tabata, Bunseki, 1994, 188.

(Received September 2, 1998)

(Accepted October 29, 1998) 